\title{
Global Change Observation Mission
}

\author{
Haruhisa Shimoda \\ Earth Observation Research Center, Japan Aerospace Exploration Agency \\ 2-1-1, Sengen, Tsukuba, Japan-shimoda@haruhisa@jaxa.jp
}

\begin{abstract}
ADEOSIIwas launched on Dec., 2002. However, after about 10 months operation, it has lost most of its power due to the solar paddle failure. As a follow on of ADEOSII mission, JAXA is now planning GCOM mission which is composed of a series of satellites. They are now called GCOM-W and GCOM-C satellites. Both satellites are composed of 3 satellites with 5 year lifetime. Hence, 13 years of continuous observation can be assured with 1 year overlaps. The first satellite of GCOM-W will be launched in fiscal 2011 while the first one of GCOM-C will be launched in fiscal 2014. GCOM-W will carry AMSR 2. AMSR 2 will be very similar to AMSR on ADEOSII and AMSR-E on EOS-Aqua with some modifications. GCOM-C will carry GLI F/O (SGLI). The SGLI will be rather different from GLI. The main targets of SGLI are atmospheric aerosols, coastal zone and land. In order to measure aerosols over both ocean and land, it will have a near ultra violet channel, as well as polarization and bi-directional observation capability. For, coastal zone and land observation, the IFOV of SGLI for these targets will be around $250 \mathrm{~m}$. The instrument will be composed of several components. The shorter wavelength region will adopt push broom scanners, while long wave region will use a conventional whisk broom scanner. There are several options on the orbit. The orbit of GCOM-W1 is A-Train (700km afternoon orbit) and that of GCOM-C1 is $800 \mathrm{~km}$ morning orbit.
\end{abstract}

\section{Kwywords:GCOM;GCOM-W,GCOM-C,SGLI;AMSR-2}

\section{INTRODUCTION}

In the late $20^{\text {th }}$ century, it has been pointed out that changes of the global environment could alter the living environment for human being. Such global environmental changes include, but not limited to, climate warming, the sea level rise, decrease of tropical forests, desertification, destruction of the ozone layer, acid rain and the decrease of bio-diversity. What makes global changes different from conventional natural fluctuations is that many of them have been taking place due to anthropogenic causes. Although these changes have not yet reached the stage of directly affecting the life of humankind, there is a possibility that they will have major impacts in the latter half of $21^{\text {st }}$ century.

For the protection and survival of humankind's future generations, it is essential to predict the future courses of these global changes so that efforts can be made to mitigate the adverse impacts of these changes. It must be said, however, that the prediction of global changes is extremely difficult. In the case of the notion of global warming caused by an increase of the atmospheric greenhouse gases like $\mathrm{CO}_{2}$, while most scientists agree with the general concept, there is no commonly agreed quantitative prediction of how and when this phenomenon will manifest itself.

The reasons for this lack of a common prediction lie with the extreme diversity of the factors determining the global climate and the complicated interaction of these factors on which little scientific knowledge has yet been established. Any adequate understanding of global changes must be based on an approach which regards the Earth as a single system within which various global geophysical parameters, processes affecting each parameter and the interaction between parameters are understood.

The establishment of various global geophysical parameters using conventional observation and measurement methods primarily based on field campaigns, however, has been found to be extremely difficult if not impossible. Satellite observation is essential for any attempt to solve global environmental problems.

\section{GCOM MISSION CONCEPT}

\subsection{Subjects of GCOM}

The GCOM aims at continuing and improving the observation conducted by the ADEOS and ADEOSIlwith a view to accumulating the scientific knowledge necessary to elucidate global environmental problems.

In regard to global warming, the GCOM intends the measurement of most factors involved in the energy and water cycle and material cycle, which are the main mechanisms determining climate change, and also analysis of the relevant processes. While the measurable geophysical parameters are detailed in 3.3 and 3.5, the parameters directly related to the energy and water cycle are temperature, water vapor, precipitation, clouds, aerosols, albedo, heat radiation from the atmosphere and estimated air-sea energy flux, etc.

Within the material cycle, measurement of the carbon cycle is a key subject. In this particular field, the GCOM aims at estimating the primary production as well as carbon flux based on measurement data on land vegetation and phytoplankton.

In regard to changes of the land environment, the measuring subjects are land cover, tropical forests and the global distribution of vegetation and their changes. In regard to the cryosphere, the sea ice concentration and snow coverage are measured and their interaction with the climate is analyzed.

\subsection{Expected Achievements of GCOM}

As a succeeding satellite in the ADEOS series beginning with the launch of the first ADEOS in 1996, the GCOM is 
expected to make the following achievements by the end of its mission (around 2020).

1) Global Warming

- Understanding of the global warming by global and longterm measurement data on various parameters.

- Separation between natural variability and trends using the data set covering the 20 year period from the launch of the ADEOS or the 15 year period from the launch of the ADEOSII.

2) Change of Land Environment

- Understanding of global forest dynamics

- Understanding of snow and ice changes

3) Clarification of sink and source of greenhouse gases.

2.3 Geophysical Parameters which will be Continuously Measured by GCOM

GCOM is a mission which continuously measures the following geophysical parameters more than 13 years.

1) Atmosphere

PAR, cloud amount, cloud type, cloud top height, optical thickness of cloud, cloud water equivalent, horizontal distribution of column water vapor, horizontal distribution of precipitation, optical thickness of aerosol, size distribution of aerosol, aerosol type

2) Ocean

chlorophyll-a, extinction coefficients, suspended solids (SS), colored dissolved organic matter (C-DOM), sea surface winds, sea surface temperature

3) Land

vegetation distribution, APAR (absorbed photosynthetic active radiation), LAI (leaf area index), Biomass, land cover, land surface reflectance, land surface temperature and emissivity, surface soil moisture over non vegetated area

4) Cryosphere

sea ice concentration, snow cover, discrimination of wet and dry snow over non vegetated area, dry snow water equivalence over non vegetated area, ice cover

\subsection{Possible Contribution to Understanding of Global Changes}

1) Global Warming

(a)Understanding of the reality of the phenomenon: global and long-term measurement data on various parameters which significantly affect global warming except for some parameters (evapotranspiration, etc.) related to the water cycle, can be retrieved.

(b)Separation between natural fluctuations and trends: using the data set covering the 15 year period from the launch of the ADEOS or the 10 year period from the launch of the ADEOSIlcovering one sun spot cycle and two or three ENSO cycles, it will be possible to separate the natural fluctuation components of the climate and trends.

(c)Understanding of the sinks/sources of GHGs

2) Change of Land Environment

(a) Understanding of global forest dynamism

(b) Understanding of snow and ice changes

\subsection{Contribution to Operational Applications}

GCOM satellites contribute not only to global change researches, but also several operational applications. Typical applications are listed below.

1) Accuracy improvements of numerical weather prediction
2) Accuracy improvements of extreme weather prediction

3) Ship navigation

4) Fisheries

5) Coastal management

6) Crop yield estimation

7) Volcanic eruptions

8) Air quality assessment including dust aerosols

9) Wild fires

\section{GCOM FIRST GENERATION SATELLITES}

\subsection{GCOM Satellites}

After the failure of ADEOSII, JAXA is now planning to launch small satellites rather than large ones. According to this strategy, ADEOSIlfollow on is now divided into two missions, i.e. GCOM-W and GCOM-C. The continuous observation required to GCOM mission poses these two missions to be composed of series of satellites, i.e., 3 satellites with 5 year life time for each mission, hence provides at least 13 years of continuous data.

GCOM-W and GCOM-C will have sun-synchronous orbit, but their local times are different. Equator crossing local time of GCOM-W will be around 13:30 at ascending node, while that of GCOM-C will be around 10:30 at descending node. These satellites will focus on energy cycle and carbon cycle. The tentative specifications of the satellites are as follows.

GCOM-W

$$
\begin{aligned}
& \text { orbit : altitude }: 700 \mathrm{~km} \\
& \text { mass }: 1.9 \text { ton } \\
& \text { power }: 4 \mathrm{~kW} \\
& \text { GCOM-C } \\
& \text { orbit : altitude }: 800 \mathrm{~km} \\
& \text { mass }: 2.0 \text { ton } \\
& \text { power }: 4 \mathrm{~kW}
\end{aligned}
$$

For the GCOM-W1 orbit, there are many user requests that GCOM-W1 should be a part of A-train. JAXA negotiated with NASA on this subject, and finally decided to join the ATrain.

\subsection{Details of GCOM-W Sensors}

GCOM-W1 will carry single instruments, i.e., AMSR-2 (Advanced Microwave Scanning Radiometer 2). The AMSR2 will be the follow on of the AMSR on board the ADEOSII and will aim at achieving the measurement of the same geophysical parameters. AMSR-2 is a total power microwave radiometer with two points calibration, i.e. deep space using cold sky mirror and on-board hot load [1]. For the absolute calibration, deep space observation by main mirror will be conducted [2].

There are several improvements from AMSR and AMSR-E. The first one is the improvement of hot load. As well known, the hot loads on board AMSR and AMSR-E had a large temperature gradient. This gradient was mainly caused by the low thermal conductivity of the hot load material and also the reflection from the surrounds by MLI over the hot load. To avoid this phenomenon, JAXA decided to add a temperature controlled reflector (TCP) over the hot load. With this TCP and several shields to avoid incident radiation from the surroundings, the temperature gradient will be less than $2 \mathrm{~K}$, and the accuracy of brightness temperature over hot load will be around $0.1 \mathrm{~K}$. 
Another problem of AMSR and AMSR-E was electromagnetic interference from the ground to $\mathrm{C}$ band data [3]. JAXA decided to add $7.3 \mathrm{GHz}$ experimental band to AMSR-2. This frequency is rather free from interference from the preliminary study over Japan and US.

AMSR-2 is a conical scanning microwave radiometer with 2 $\mathrm{m}$ aperture parabolic antenna. The incidence angle is $55^{\circ}$ and the swath width is more than $1,420 \mathrm{~km}$ in the case of $700 \mathrm{~km}$ altitude orbit.

\begin{tabular}{|l|l|l|l|l|}
\hline $\mathrm{a}$ & $\mathrm{b}$ & $\mathrm{c}$ & $\mathrm{d}$ & $\mathrm{e}$ \\
\hline 6.9 & 50 & 350 & 0.3 & 12 \\
7.3 & 50 & 350 & 0.3 & 12 \\
10.65 & 50 & 100 & 0.6 & 12 \\
18.7 & 25 & 200 & 0.6 & 12 \\
23.8 & 25 & 400 & 0.5 & 12 \\
36.5 & 15 & 1000 & 0.5 & 12 \\
89.0 & 5 & 3000 & 1.0 & 12 \\
\hline
\end{tabular}

Tentative specification $s$ of AMSR2 are shown in Table 1.

Table 1 Tentative specifications of AMSR-2.
a : central frequency $(\mathrm{GHz})$
$\mathrm{b}:$ ground resolution $(\mathrm{km})$
$\mathrm{c}:$ bandwidth $(\mathrm{MHz})$
$\mathrm{d}: \mathrm{NEdT}$
e : quantization bits

\subsection{Products from GCOM-W [4]}

Standard products from GCOM-W are listed below.

1) brightness temperature

2) total water vapor

3) total cloud liquid water

4) precipitation

5) sea surface temperature

6) sea surface wind speed

7) sea ice concentration

8) snow amount

\begin{tabular}{|c|c|c|c|c|c|c|c|}
\hline 9) soil & Ch. & $\mathrm{a}$ & $\mathrm{b}$ & $\mathrm{c}$ & $\mathrm{f}$ & $\mathrm{g}$ & $\mathrm{h}$ \\
\hline mors & 1 & 1.05 & 1000 & 0.02 & 57 & 248 & 300 \\
\hline ure & 2 & 1.38 & 1000 & 0.02 & 8 & 103 & 150 \\
\hline & 3 & 1.64 & 250 & 0.2 & 3 & 50 & 57 \\
\hline & 4 & 2.21 & 1000 & 0.05 & 1.9 & 20 & 211 \\
\hline eta & 5 & 10.8 & 500 & 0.7 & 300 & 340 & 0.2 \\
\hline Cr & 6 & 12.0 & 500 & 0.7 & 300 & 340 & 0.2 \\
\hline
\end{tabular}

M-C Sensor

GCOM-C will carry only one instrument, i.e. SGLI (Second Generation Global Imager). The SGLI sensor will be a multipurpose visible, near infrared, shortwave infrared and thermal infrared imager and an advanced version of the GLI. It will be capable of measuring ocean color, land cover and vegetation, snow and ice, clouds, aerosols and water vapor, etc. The different characteristics with GLI are as follows.

a) The largest target of SGLI is to retrieve global aerosol distributions. In order to achieve this target, SGLI will have 2 polarization channels with 3 directions. b) SGLI is mainly focused to land and coastal areas. There are $11250 \mathrm{~m}$ IFOV channels compared to 6250 channels in GLI.

c) VNR component of SGLI is a push broom scanner.

The components of the SGLI are as follows.

(a) Visible and Near-Infrared (VNR): 11 channel visible and near infrared push broom scanner.

(b) Polarization : 2 visible channels with 3 polarizations and 3 directions push broom scanner

(c) Shortwave and Thermal Infrared (SWI \& TMI): 4 channel shortwave and 2 channel thermal infrared

\begin{tabular}{|l|l|l|l|l|l|l|}
\hline Ch. & a & b & c & d & e & S/N \\
\hline VN1 & 380 & 250 & 10 & 60 & 210 & 250 \\
\hline VN2 & 412 & 250 & 10 & 75 & 250 & 400 \\
\hline VN3 & 443 & 250 & 10 & 64 & 400 & 300 \\
\hline VN4 & 490 & 250 & 10 & 53 & 120 & 400 \\
\hline VN5 & 530 & 250 & 20 & 41 & 350 & 250 \\
\hline VN6 & 565 & 250 & 20 & 33 & 90 & 400 \\
\hline VN7 & 673.5 & 250 & 10 & 23 & 62 & 400 \\
\hline VN8 & 673.5 & 250 & 20 & 25 & 210 & 250 \\
\hline VN9 & 868.5 & 250 & 20 & 8 & 30 & 400 \\
\hline VN10 & 763 & 1000 & 40 & 350 & 350 & 400 \\
\hline VN11 & 868.5 & 250 & 20 & 30 & 300 & 200 \\
\hline \multicolumn{7}{|c|}{ optical mechanical scanner }
\end{tabular}

The details of tentative radiometric specifications of VNR are shown in Table 2(a).

Table 2 (a) specifications of VNR

$$
\begin{aligned}
& a: \text { center wavelength } \\
& \mathrm{b}: \text { IFOV } \\
& \mathrm{c}: \text { channel width } \\
& \mathrm{d}: \text { standard radiance to define } \mathrm{S} / \mathrm{N} \\
& \mathrm{e}: \text { maximum radiance }
\end{aligned}
$$

The details of tentative specifications of polarization

\begin{tabular}{|l|l|l|l|l|l|l|}
\hline Ch. & $\mathrm{a}$ & $\mathrm{b}$ & $\mathrm{c}$ & $\mathrm{d}$ & $\mathrm{e}$ & $\mathrm{S} / \mathrm{N}$ \\
\hline 670-P1 & 673.5 & 1000 & 20 & 25 & 250 & 250 \\
\hline 670-P2 & 673.5 & 1000 & 20 & 25 & 250 & 250 \\
\hline 670-P3 & 673.5 & 1000 & 20 & 25 & 250 & 250 \\
\hline $865-\mathrm{P} 1$ & 868.5 & 1000 & 20 & 30 & 300 & 250 \\
\hline 865-P2 & 868.5 & 1000 & 20 & 30 & 300 & 250 \\
\hline $865-\mathrm{P} 3$ & 868.5 & 1000 & 20 & 30 & 300 & 250 \\
\hline
\end{tabular}

channels are shown in Table 2(b).

The swath widths of both VNR and polarization channels are $1050 \mathrm{~km}$

Table 2(b) specifications of polarization channels

The details of tentative specifications of IRS (SWI \& TMI) are shown in Table 2(c).

Table 2(c) Specifications of IRS

$\mathrm{f}$ : standard radiance to define $\mathrm{S} / \mathrm{N}$ or standard temperature

$\mathrm{g}$ : maximum radiance or maximum temperature

$\mathrm{h}: \mathrm{S} / \mathrm{N}$ or NEdT 


\subsection{Products of GCOM-C [4]}

Standard products from GCOM-C are listed below

Land

1) radiance

2) surface reflectance

3) vegetation index

4) vegetation roughness index,

5) shadow index

6) land surface temperature

7) FAPAR

8) LAI

9) above ground biomass

\section{Atmosphere}

1) cloud flag

2) cloud amount

3) cloud top height \& temperature

4) water cloud optical depth \& size

5) cirrus droplet size

6) aerosol over ocean

7) aerosol over land (near UV)

8) aerosol over land (polarization)

Ocean

1) normalized water leaving radiance

2) atmospheric correction parameter

3) PAR

4) Chlorophyll-a

5) suspended solids

6) $\mathrm{CDOM}$

7) $\mathrm{SST}$

\section{Cryosphere}

1) snow \& sea ice distribution

2) ice distribution over Okhotsk sea

3) snow \& ice surface temperature

4) shallow snow particle size

\subsection{GCOM-W2}

Now, the GCOM-W2 discussions have started. For GCOMW1, there are no scatterometer. However, from the experience of AMSRII, the synergy of a microwave radiometer and a scatterometer gave us higher accuracies to both sensor products, as well as new products. Now JAXA is negotiating with NOAA and JPL for the provision of a microwave scatterometer to GCOM-W2. This scatterometer is an advanced scaterometer compared to the past and existing scatterometers. It will have two channels, i.e. a $\mathrm{Ku}$ band and a $\mathrm{C}$ band, and will have a larger aperture of around $2 \mathrm{~m}$.

Also the improvement of AMSR2 is under discussion by JAXA and users. New specification requirements includes a larger aperture as well as the addition of higher frequency channels for snow, water vapor, etc.

\section{References}

[1] Colton M.C. and G.A. Poe, "Intersensor calibration of DMSP SSM/I's : F-8 to F-14, 1987-1997”, IEEE Trans.

Geosci. Remote Sensing, vol.37(1), pp.418-422, 1999.

[2] Jones W.L., Park J.D., Soisuvarn S., et al., "Deep-space calibration of the Windsat radiometer", IEEE Trans. Geosci. Remote Sensing, vol.44(3), pp.476-495, 2006.
[3] JAXA, "Improved Advanced Microwave Radiometer (AMSR-E) on-board Aqua Stationary Operation Completion Review Report", JAXA technical document SDA-050005, 2005. (in Japanese)

[4] JAXA, "GCOM mission requirement specifications", JAXA technical document SAP-060001, 2006. (in Japanese) 